\title{
Research on Power Dispatching Modes Based on the Thermal Performance of District Heating System
}

\author{
Qionghui Li ${ }^{1}$, Qingsong Zhao ${ }^{2}$, Chenggang Liu ${ }^{3}$, Wei Yuan ${ }^{1}$, Yong Wang ${ }^{4}$, Xiaoning Ye ${ }^{1}$, Caixia Wang $^{1}$, and Yang Liu ${ }^{5}$ \\ ${ }^{1}$ State Grid Energy Research Institute Co. LTD Beijing, China \\ ${ }^{2}$ Electric Power Research Institute of State Grid Liaoning Electric Power Co. LTD \\ ${ }_{3}^{3}$ Inner Mongolia Electric Power Science and Research Institute, Hohhot, 01002, China \\ ${ }^{4}$ State Grid Liaoning Electric Power Co. LTD \\ ${ }^{5}$ Northeast Branch of State Grid Corporation of China
}

\begin{abstract}
Recently in winter, there appears serious wind abandoning problem in "Three North" (Northeast, Northwest and North China) regions, and the peak regulation become much more difficult in electric power grid system. So the operation mode of cogeneration for electric peak-load regulation is discussed without energy storage system, which will lead to the fluctuation of heating load and the fluctuation of supply water temperature. In this article, two different power dispatching modes are put forward and the influence is analyzed. From the simulation result, the indoor air temperature amplitudes of the two modes just have slightly different. Return water temperature amplitude of the mode II is obviously smaller than mode I. Compared with the real-time power load of Beijing-Tianjin-Hebei Region, mode II is smoother than mode I, and the difference between real-time load and dispatching load of mode II is smaller than that of mode I.
\end{abstract}

\section{Introduction}

During winter, in Chinese "Three North" region, high penetration of both cogeneration and wind power which has anti-peak shaving feature, results in serious operation difficulty of electric power system and wind abandoning problem. In order to consume the abandoned wind power, researchers mainly investigate in electric heating and wind-energy storage system [1,2]. While in traditional cogeneration, power is ordered by heat, if cogeneration can participate in power peak shaving, the problem will be significantly improved. An operation mode of a cogeneration as an electric peak-load regulating is put forward in [3]. If energy storage system is not available, the operation will lead the fluctuation of the heating load and supply water temperature, which has been analyzed through dynamic thermal performance of district heating system in [4]. At present, energy storage system is difficult to apply in cogeneration. So in this article, two different power dispatching modes are put forward and the influence of each mode is analyzed and compared.

\section{Thermal performance of district heating system}

In order to analyze dynamic thermal performance of district heating system, this paper introduces a hierarchical structure and performed a harmonic response method in Fig. 1.[4]. The Green's function is used as the transfer function to study attenuation coefficient and delay coefficient in different hierarchy.

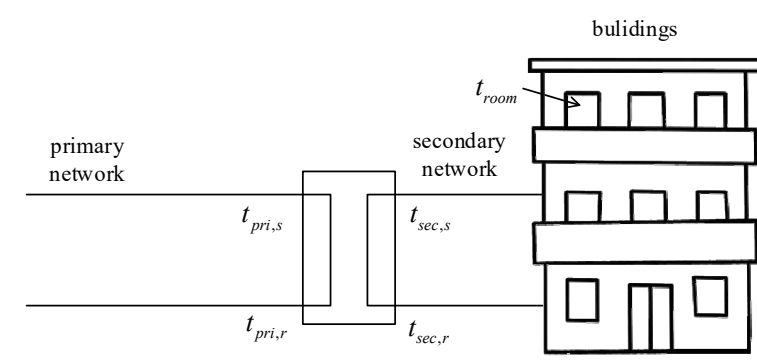

Fig. 1. Hierarchy of a Typical District Heating System

Dynamic thermal performance of district heating system is considered as a periodic problem, so trigonometric function and Fourier expansion is introduced in the paper. In order to analyze attenuation and delay coefficients, supply water temperature of primary network is considered as a sum of average temperature and a trigonometric function.

$$
T_{p r i, s}(\tau)=\overline{t_{p r i, s}}+t_{p r i, s}=\overline{t_{p r i, s}}+A \sin (\omega \tau+\varphi)
$$

According to the data [4], attenuation multiple and phase delay between supply water temperature of primary network and indoor air temperature in different period can be calculated.

\footnotetext{
* Corresponding author:yuanwei@sgeri.sgcc.com.cn
} 


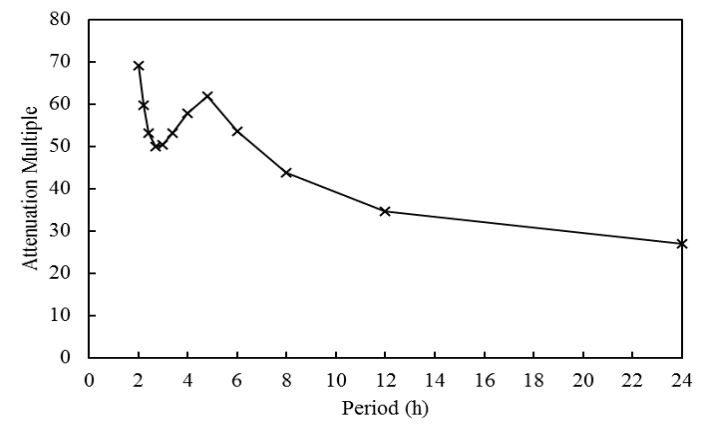

Fig. 2. Attenuation Multiple of Indoor Air Temperature

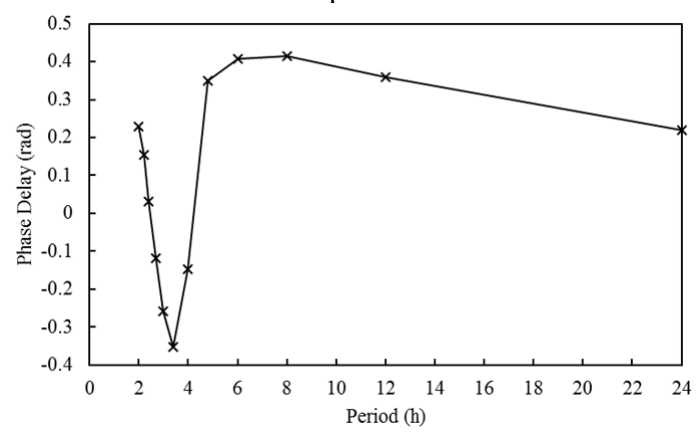

Fig. 3. Phase Delay of Indoor Air Temperature

The transfer function between supply water temperature of primary network and return water temperature of primary network can be described below.

$$
\frac{t_{p r i, r}(\omega)}{t_{p r i, s}(\omega)}=G_{p r i, r}(\omega)
$$

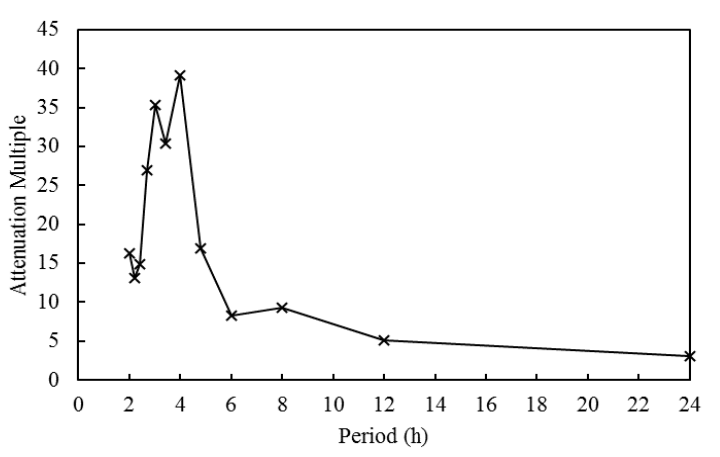

4. Attenuation Multiple of Return Water Temperature

Fig.

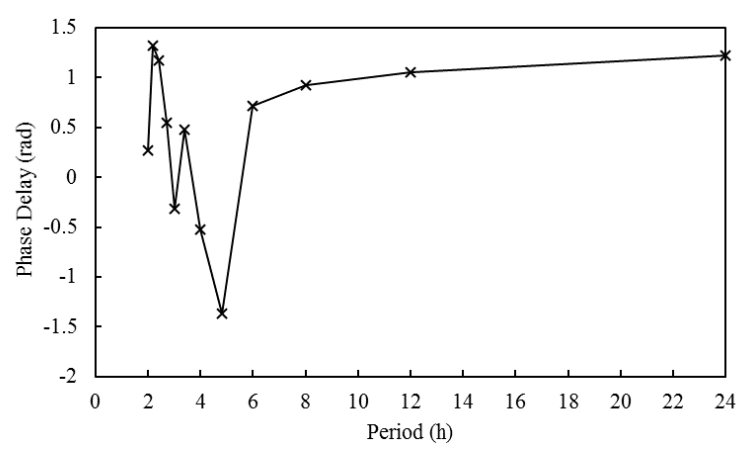

Fig. 5. Phase Delay of Return Water Temperature for Different Period

\section{Analysis of Dispatching Modes}

\subsection{Dispatching Mode I}

Square wave with unit amplitude of mode I is put forward, and through Fourier expansion return water temperature of primary network and indoor air temperature can be calculated as follows.

$$
\begin{aligned}
& t_{t_{\text {room }}}=\frac{4}{\pi} \sum_{n=1}^{6} \frac{1}{2 n-1} \frac{1}{\eta_{\text {room }}\left((2 n-1) \frac{2 \pi}{T}\right)} \sin \left(\frac{(2 n-1) \times 2 \pi x}{T}+\vartheta_{\text {room }}\left((2 n-1) \frac{2 \pi}{T}\right)\right) \\
& t_{\text {pri, }}=\frac{4}{\pi} \sum_{n=1}^{6} \frac{1}{2 n-1} \frac{1}{\eta_{p r i, r}\left((2 n-1) \frac{2 \pi}{T}\right)} \sin \left(\frac{(2 n-1) \times 2 \pi x}{T}+\vartheta_{\text {pri, }}\left((2 n-1) \frac{2 \pi}{T}\right)\right)
\end{aligned}
$$

Where, $T=24 \mathrm{~h}$, the result is put forward as follows Fig. 6 .

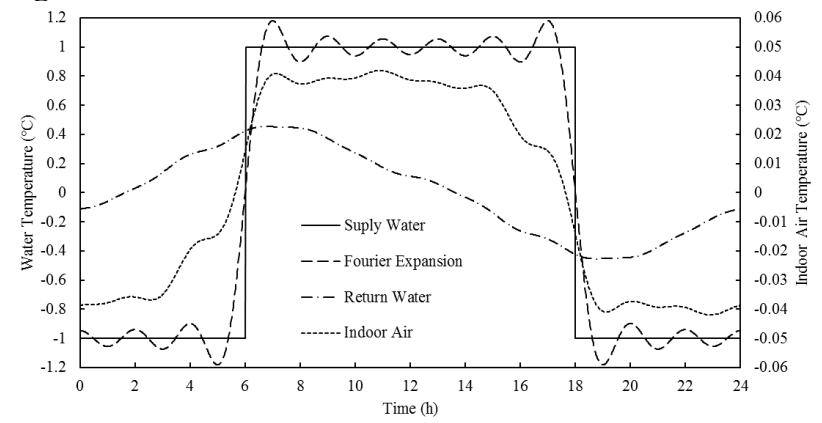

Fig. 6. Fourier Expansion and Temperature Response Analysis in Mode I

In the Fig. 6, the amplitude of supply water temperature is unit value $\left(1^{\circ} \mathrm{C}\right)$. The amplitude of return water temperature is $0.45^{\circ} \mathrm{C}$, and the amplitude of indoor air temperature is $0.042^{\circ} \mathrm{C}$. So the attenuation multiple of return water temperature is 2.2 , and the attenuation multiple of indoor air temperature is 23.8. In dispatching mode I, the amplitude of supply water temperature is $9.0^{\circ} \mathrm{C}$, and the amplitude of return water temperature is $4.1^{\circ} \mathrm{C}$, and the amplitude of return water temperature is $0.38^{\circ} \mathrm{C}$. According to the Fig. 6, the actual return water temperature varies from $45.9^{\circ} \mathrm{C}$ to $54.1^{\circ} \mathrm{C}$. And indoor air varies from $17.6^{\circ} \mathrm{C}$ to $18.4^{\circ} \mathrm{C}$.

\subsection{Dispatching Mode II}

Fourier expansion return water temperature of primary network and indoor air temperature can be calculated as follows.

$$
\begin{aligned}
& t_{\text {room }}=\frac{4}{\pi} \sum_{n=1}^{12} \frac{1}{n} \sin \frac{n \pi}{3} \sin \frac{n \pi}{2} \frac{1}{\eta_{\text {room }}\left(\frac{2 n \pi}{T}\right)} \sin \left(\frac{2 n \pi x}{T}+\vartheta_{\text {room }}\left(\frac{2 n \pi}{T}\right)\right)(5) \\
& t_{\text {pri, },}=\frac{4}{\pi} \sum_{n=1}^{12} \frac{1}{n} \sin \frac{n \pi}{3} \sin \frac{n \pi}{2} \frac{1}{\eta_{\text {pri, }}\left(\frac{2 n \pi}{T}\right)} \sin \left(\frac{2 n \pi x}{T}+\vartheta_{\text {pri, }}\left(\frac{2 n \pi}{T}\right)\right)(6)
\end{aligned}
$$

Where, $T=24 \mathrm{~h}$, the result is put forward in Fig. 7 . The amplitude of supply water temperature is unit value $\left(1{ }^{\circ} \mathrm{C}\right)$. The amplitude of return water temperature is $0.36^{\circ} \mathrm{C}$, and the amplitude of indoor air temperature is $0.041^{\circ} \mathrm{C}$. So the attenuation multiple of return water temperature is 2.8 , and the attenuation multiple of indoor air temperature is 24.2. In Fig. 7 the dispatching mode II, the amplitude of supply water temperature is $9.0^{\circ} \mathrm{C}$, so 
amplitude of return water temperature is $3.2^{\circ} \mathrm{C}$, and amplitude of return water temperature is $0.37^{\circ} \mathrm{C}$. According to the Fig. 7 above, the actual return water temperature can be calculated and it varies from $46.8^{\circ} \mathrm{C}$ to $53.2^{\circ} \mathrm{C}$. The indoor air varies from $17.6^{\circ} \mathrm{C}$ to $18.4^{\circ} \mathrm{C}$.

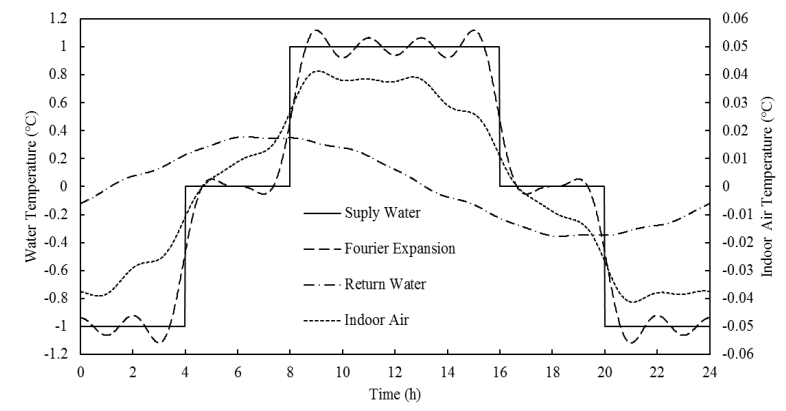

Fig. 7. Fourier Expansion and Temperature Response Analysis in Mode II

\subsection{Comparison of the Two Modes}

The indoor air temperature variation of the two modes are almost the same, and the temperature amplitude in mode II is slightly smaller than mode I in Fig. 8.

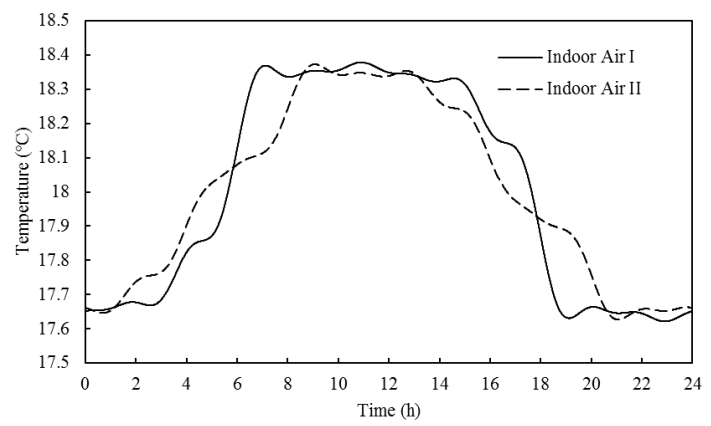

Fig. 8. Indoor Air Temperature Comparison

However, in Fig. 9, the return water temperature amplitude of primary network in mode II is obviously smaller than that in mode I.

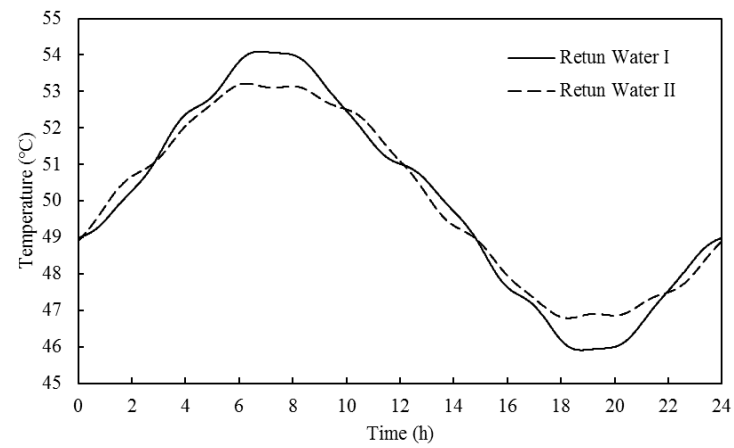

Fig. 9. Return Water Temperature of Primary Network Comparison
In design, return water temperature of primary network is considered as a constant, but in fact, the water temperature varies according to supply water temperature of primary network. And the variation is calculated in the above. So a revising is needed. In the revised dispatching mode, supply water temperature of primary network is the same as the design condition. So the heating load will be changed because of the difference between actual return water temperature of primary network and design return water temperature of primary network. The difference will be descripted by heating rate as follows.

$$
\eta_{\text {heating }}=\frac{T_{s, \text { design }}-T_{r, \text { actual }}}{T_{s, \text { design }}-T_{r, \text { design }}}
$$

The heating rates for mode I and mode II are put forward in Fig. 10 \& Fig. 11 respectively.

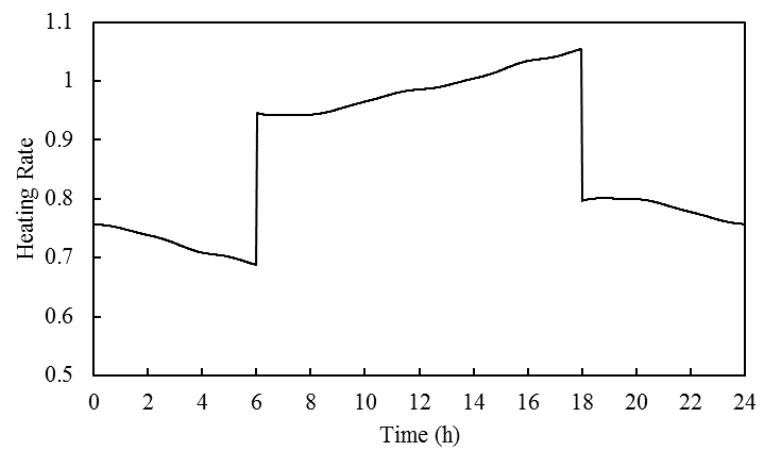

Fig. 10. Heating Rate Based on Return Water Temperature Revising for Mode I

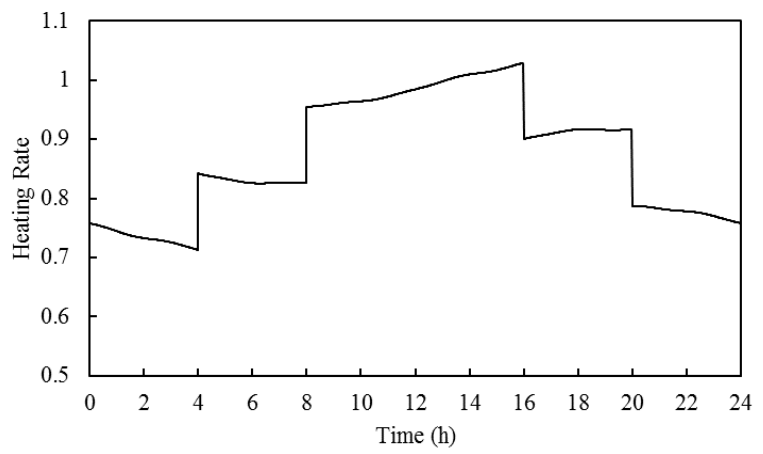

Fig. 11. Heating Rate Based on Return Water Temperature Revising for Mode II

In the cogeneration, high back pressure heating is analyzed, so that the fluctuation of the power load is equal with heating load. So the revised power dispatching for mode I and mode II, are put forward in Fig. 12 \& Fig. 13 respectively.

\section{Dispatching Mode Revising}

\subsection{Mode revising}




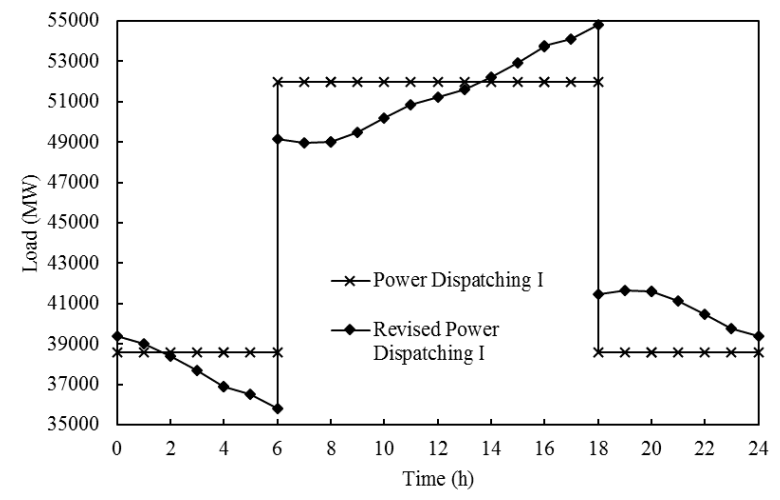

Fig. 12. Design \&Revised Power Dispatching I

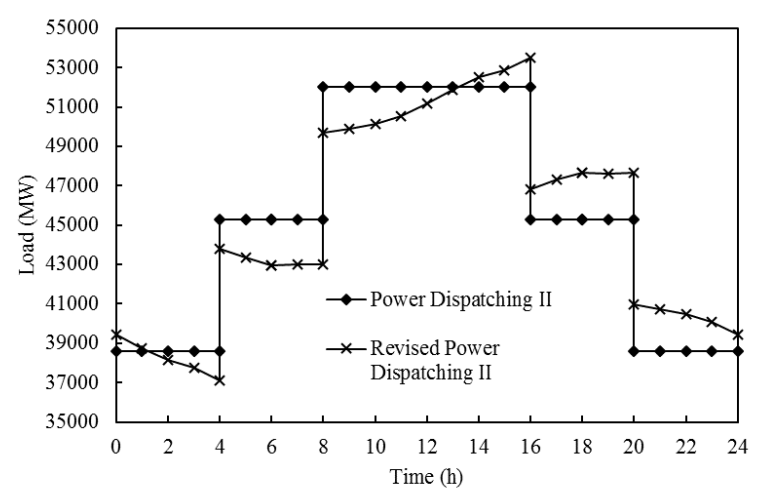

Fig. 13. Design \& Revised Power Dispatching II

\subsection{Comparison of Revised Modes}

Compared to the real-time power load of BeijingTianjin-Hebei Region, obviously mode II is smoother than mode I, and the difference between real-time load and dispatching load of mode II is smaller than mode I.

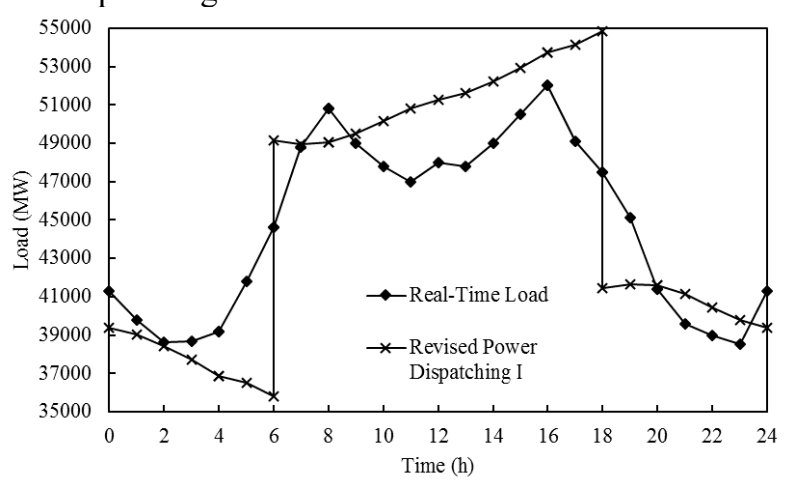

Fig. 14. Revised Power Dispatching I \& Real-Time Load

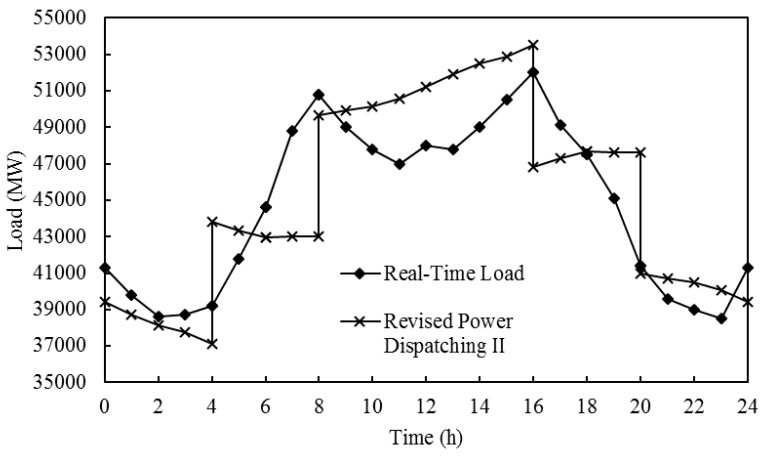

Fig. 15. Revised Power Dispatching II \& Real-Time Load

\section{Conclusion}

Based on the power load of a typical day in winter of Beijing-Tianjin-Hebei region, two different design dispatching modes are put forward in the article, which are two kinds of square wave. In order to calculate the response temperature of return water and indoor air, the Fourier expansions of the two kinds of square wave are introduced. According to the solution of the dynamic thermal performance of district heating system of sine wave, the response temperature of return water and indoor air is calculated. The indoor air temperature amplitudes of the two modes just appear slightly different. However, the return water temperature amplitude of the mode II is obviously small than that of the mode I. Based on the response temperature of return water, two dispatching modes are revised and actual dispatching modes are put forward. Compared to the real-time power load of Beijing-Tianjin-Hebei Region, mode II seems smoother than mode I, and the difference between real-time load and dispatching load of the mode II is smaller than that of the mode I.

\section{References}

1. Diaz-Gonzalez F, Sumper A, Gomis-Bellmunt O, Villafafila-Robles R. A review of energy storage technologies for wind power applications [J]. Renewable and Sustainable Energy Reviews. 16, 18 (2012)

2. Hessami MA, Bowly DR. Economic feasibility and optimization of an energy storage system for Portland Wind Farm (Victoria, Australia) [J]. Appl Energy. 88, 9 (2011)

3. Fu Lin. Operation of a cogeneration Plant as an Electric Peak-Load Regulation Plant [D]. Beijing: Tsinghua University, (1999)

4. Qin Bing. Studies on the Dynamic Thermal Characteristics of District Heating Systems [D]. Beijing: Tsinghua University, (2004) 